\title{
No Association Between the 5-HTTLPR Polymorphism and Diurnal Preference in Koreans
}

\author{
Sae Han Kim', Ji Won Yeom,2, Seunghwa Jeong ${ }^{1,2}$, \\ Ju Yeon Seo ${ }^{1,2}$, Sehyun Jeon ${ }^{1,2}$, and Heon-Jeong Lee Le, $^{1,2}$ \\ 'Department of Psychiatry, Korea University Anam Hospital, Korea University College of Medicine, Seoul, Korea \\ ${ }^{2}$ Chronobiology Institute, Korea University, Seoul, Korea
}

\begin{abstract}
Objective: Recent studies have extended the study of diurnal preferences to the genetic level. Most studies have focused on clock genes, but some studies have searched for the possibilities of other genes associated with the circadian rhythm. Considering that the circadian rhythm is associated with the serotonergic system, investigating the association between major genes of the serotonin system and the diurnal preference phenotype is essential. In this study, we evaluated whether the 5-HTTLPR polymorphism is associated with diurnal preference in a Korean population. Methods: In total, 509 healthy subjects were genotyped for the 5-HTTLPR polymorphism. The Korean version of the Composite Scale of Morningness (CSM) was used to measure the phenotype patterns of diurnal preference. In addition, scores of three subscales-morningness, activity planning, and morning alertness-were extracted from the CSM. Results: No significant associations were observed between CSM scores and the 5-HTTLPR genotype or allele carrier status. Conclusion: The results of this study suggests that 5-HT$T L P R$ has no effect on diurnal preference in a healthy Korean population. Further studies with a large number of subjects from multiple ethnicities are necessary to fully evaluate the association between 5-HTTLPR and diurnal preference.
\end{abstract}

Keywords: Diurnal preference; 5-HTTLPR; Polymorphism; Morningness; Circadian rhythm

Received: August 31, 2021 Revised: September 8, 2021 Accepted: September 8, 2021

Corresponding author: Heon-Jeong Lee, MD, PhD, Department of Psychiatry, Korea University Anam Hospital, Korea University College of Medicine, 73 Goryeodae-ro Seongbuk-gu, Seoul 02841, Korea.

Tel: 82-2-920-6721, Fax: 82-2-6280-5810, E-mail: leehjeong@korea.ac.kr

@ This is an Open Access article distributed under the terms of the Creative Commons Attribution Non-Commercial License (https://creativecommons.org/licenses/bync/4.0) which permits unrestricted non-commercial use, distribution, and reproduction in any medium, provided the original work is properly cited.

\section{INTRODUCTION}

Diurnal preference is a circadian typology consisting of three chronotypes-morning, evening, and neither types. Morningtype individuals sleep and wake up early and achieve most of their peak mental and physical performance in the early part of the day. In contrast, evening-type individuals sleep and wake up late, showing their best performance mostly during the evening hours [1]. According to many studies, compared to morning-type individuals, evening type individuals have more negative health consequences, such as mood disorders, anxiety disorders, substance use disorders, autism, personality disorders, insomnia, sleep apnea, hypertension, diabetes, and infertility [2]. Diurnal preference has interpersonal variations due to differences in age, sex, and genetic and environmental factors that could influence circadian rhythms [3,4].
The circadian rhythm is a roughly 24 -hour cycle related to the sleep/wake cycle, locomotor activity rhythm, and the secretion rhythm of various hormones. It is endogenously generated by a defined neural network located in the suprachiasmatic nucleus (SCN) of the anterior hypothalamus and various "clock genes," which drive the neural circadian rhythms through daily autoregulatory transcription/translation feedback oscillations $[5,6]$.

In addition to clock genes, the circadian rhythm is associated with the serotonergic system in the brain [7]. The brain's serotonergic system is located in the midline raphe nucleus of the midbrain, pons, and medulla and contains an extensive network of efferents to the cortex, thalamus, hypothalamus, and limbic system.

The circadian and serotonergic systems are extensively intertwined in both neuroanatomical and physiological aspects. The $\mathrm{SCN}$ receives direct serotonergic innervation from the raphe nucleus and indirect dorsal raphe-driven neuropeptide Y input from 
the intergeniculate leaflet. The dorsal raphe nucleus receives input back from the SCN [8]. Serotonin, a neurotransmitter, not only modulates the response of the circadian system to light by inhibiting retinal inputs to the SCN neurons but also affects the circadian phase via behavioral arousal and feedback from locomotor activity $[9,10]$. The brain's serotonergic system operates in a circadian manner, and many molecules of the serotonin signaling network, such as SERT, 5-HT1B, 5-HT2C, and 5-HT7 receptors, are expressed in the SCN [7]. Tryptophan hydroxylase, the rate-limiting enzyme for serotonin synthesis, and the serotonin concentration in the raphe nucleus is regulated by the circadian rhythm [11].

Recent studies have extended the study of diurnal preferences to the genetic level. Circadian genes, such as CLOCK, PER2, PER3, $C R Y 1, A R N T L$, and $R O R a$, have been investigated for their association with diurnal preference, but many studies did not find any statistical significance or failed to replicate previous positive finding [12-16]. Yeom et al. [17] suggested that HTR2A, a gene encoding one of the serotonin receptors, is associated with diurnal preference. Considering the close relationship between the serotonergic and circadian system, this finding seems to be reasonable and leads to the possibility that some other serotonergic genes are associated with diurnal preference.

One candidate for such an investigation is 5-HTTLPR. 5-HTTLPR is a promoter region of SLC6A4, a gene encoding the serotonin transporter. The polymorphism of 5-HTTLPR involves two common allelic variations - the short (S) allele and the long (L) allele. Compared to the $\mathrm{L}$ allele, the $\mathrm{S}$ allele is associated with a lower expression of the serotonin transporter (5-HTT), which reuptakes serotonin, resulting in an increase in synaptic serotonin concentration [18]. Studies suggest that the $\mathrm{S}$ allele is associated with individuals' psychological and physiological responses to life stressors and is clinically associated with various neuropsychiatric disorders, including mood disorders, seasonal affective disorders, anxiety personality traits, substance use disorders, attention deficit hyperactivity disorder, and autism [19-24].

Given the effect of the serotonin system on the circadian rhythm, further investigation of the association between major genes of the serotonin system and the diurnal preference phenotype is essential. Furthermore, marked similarity between the range of disorders associated with the evening type of the diurnal preference and the 5-HTTLPR S allele makes 5-HTTLPR a good candidate gene for research. In this study, we examined the association between diurnal preference and the 5-HTTLPR polymorphism in healthy Korean adults. We assessed the effects of genotype and allele carrier status on the mean total score of the Korean version of the Composite Scale of Morningness (CSM) and the mean scores of its three subscales (morningness, morning alertness, and activity planning). We hypothesized that the 5-HTTLPR is associated with the evening type of diurnal preference, indicated by low mean total and subscale scores of the CSM.

\section{METHODS}

\section{Subjects}

A sample of 510 healthy Korean adults was recruited through an online advertisement, and one participant was excluded due to missing information. Participants were unrelated Korean adults who resided in Seoul $\left(37^{\circ} 41^{\prime} \mathrm{N}, 127^{\circ} 02^{\prime} \mathrm{E}\right)$ aged $18-35$ years (mean \pm standard deviation [SD], 23.4 \pm 2.8 years). There were 302 (59.3\%) men and 207 (40.7\%) women. Participants were confirmed to be free of lifetime or current psychiatric disorders by an experienced psychiatrist through a mini-international neuropsychiatric interview. The study participants did not have any major medical problems. Participants with a family history of substance abuse or major psychiatric disorders (e.g., schizophrenia or major mood disorders) were excluded. All participants provided informed consent prior to enrollment in the study. The study protocol was approved by the Ethics Committee of Korea University (IEC No. 1067), and the study was conducted in accordance with the Declaration of Helsinki. Other findings related to these participants have been reported previously [12,16,17,25-27].

\section{Diurnal preference assessment}

Diurnal preference was measured using the CSM [28]. The CSM is a 13-item scale that is considered as accurate as the Horne and Ostberg's Morningness-Eveningness Questionnaire, but it is shorter in length $[28,29]$. The CSM is an added-score scale with items, with scores ranging from 1 to 4 or 5 . The total score of the CSM ranges from 13 (extreme evening type) to 55 (extreme morning type), with higher scores indicating a greater degree of morning preference. According to previous studies, CSM items can be further classified into three subscales-morningness (items 1, 3, $6,8,10$, and 11 ), activity planning (items $2,7,9$, and 13 ), and morning alertness (items 4, 5, and 12) [30]. All participants were asked to complete the Korean version of the CSM verified by Yoon et al. [31].

\section{Genotyping}

Genomic DNA was extracted from leukocytes using the QIAamp DNA Blood Mini Kit (QIAGEN, Hilden, Germany). For the polymerase chain reaction (PCR) analysis of 5-HTTLPR, the forward primer 5'-GGC GTT GCC GCT CTG AAT TGC-3' and reverse primer 5'-GAG GGA CTG AGC TGG ACA ACC CAC-3' were used. PCR amplification was performed using a $25 \mu \mathrm{L}$ solution containing $10 \mathrm{mM}$ Tris- $\mathrm{HCl}$ (pH 8.3), $50 \mathrm{mM} \mathrm{KCl,} 1.5 \mathrm{mM} \mathrm{MgCl}_{2}$, $200 \mu \mathrm{M}$ of each dNTP, $0.25 \mu \mathrm{M}$ of each primer, $1 \mathrm{U}$ of Taq DNA polymerase, and $40 \mathrm{ng}$ genomic DNA. The conditions used for PCR amplification included initial denaturation at $94^{\circ} \mathrm{C}$ for 5 min, followed by 35 cycles at $94^{\circ} \mathrm{C}$ for $30 \mathrm{~s}, 60^{\circ} \mathrm{C}-61^{\circ} \mathrm{C}$ for $30 \mathrm{~s}$, $72^{\circ} \mathrm{C}$ for $40 \mathrm{~s}$, and final elongation at $72^{\circ} \mathrm{C}$ for $7 \mathrm{~min}$. PCR products were separated on $3 \%$ agarose gels supplemented with ethidium bromide to allow identification of the long (528 bp) and short (484 bp) variants. 
Table 1. CSM scores in subject groups according to the 5-HTTLPR polymorphism

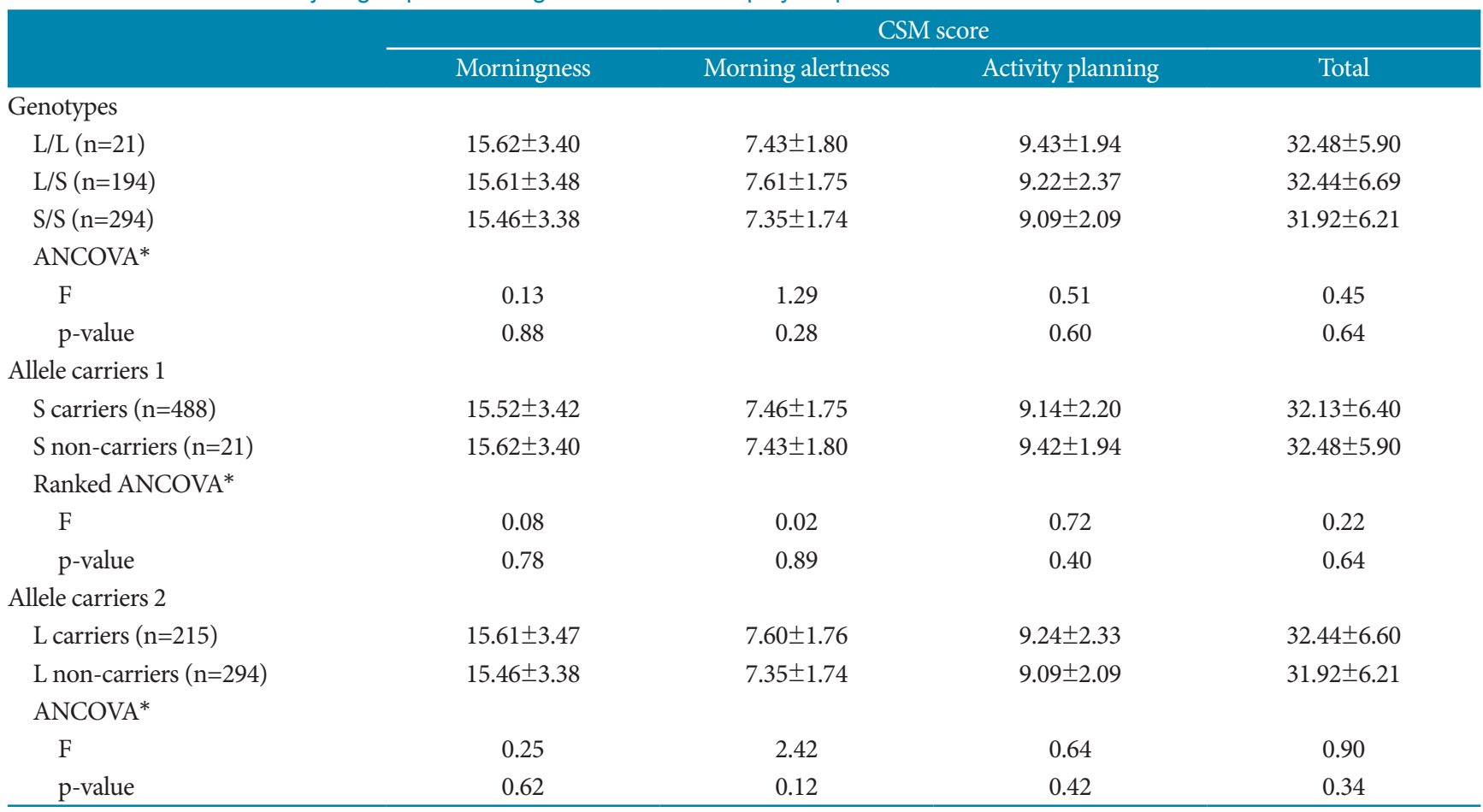

Data are presented as mean \pm standard deviation. * covariant: age, sex. CSM, Composite Scale for Morningness; ANCOVA, analysis of covariance

\section{Statistical analysis}

The chi-square $\left(\chi^{2}\right)$ test was used to test the goodness-of-fit of the Hardy-Weinberg equilibrium. Analysis of covariance (ANCOVA) with sex and age as covariates was performed to examine the effects of genotypes on the mean total CSM score and mean scores of the three CSM subscales (morningness, activity planning, and morning alertness). To examine the effects of $S$ allele carrier status (allele carriers 1 in Table 1) and L allele carrier status (allele carriers 2 in Table 1) on the mean total CSM and its subscale scores, ranked ANCOVA and ANCOVA with sex and age as covariates were performed, respectively. A two-tailed test with alpha $=0.05$ was chosen for the analysis. All statistical analyses were performed using SPSS version 22.0, for Windows (IBM Corp., Armonk, NY, USA).

\section{RESULTS}

The total CSM mean score was $32.14 \pm 6.38$, with a range of 14 to 51 . Table 1 shows the mean of the total CSM score and the three subscale scores of the groups classified based on the 5-HTTLPR polymorphisms, either divided by genotype or allele carrier status. The genotypic distributions of the 5-HTTLPR polymorphisms in the enrolled subjects were in Hardy-Weinberg equilibrium, and no significant differences were found between the observed and expected values $\left(\chi^{2}=2.50, p=0.29\right)$. In addition to genotype comparisons, the study subjects were compared according to their allele carrier status. The frequency of the $S$ allele at 5-HTTLPR in our sample population was $76.8 \%$.

No significant differences were observed in the mean total
CSM scores and mean scores of the three subscales among the genotypes of the 5-HTTLPR polymorphisms $(\mathrm{F}=0.45, \mathrm{p}=0.64$ for total CSM; $\mathrm{F}=0.13, \mathrm{p}=0.88$ for morningness; $\mathrm{F}=1.29, \mathrm{p}=0.28$ for morning alertness; $\mathrm{F}=0.51, \mathrm{p}=0.60$ for activity planning). There were no significant differences between $\mathrm{S}$ carriers and non-carriers $(\mathrm{F}=0.22, \mathrm{p}=0.64$ for total CSM; $\mathrm{F}=0.08, \mathrm{p}=0.78$ for morningness; $\mathrm{F}=0.02, \mathrm{p}=0.89$ for morning alertness; and $\mathrm{F}=0.72, \mathrm{p}=0.40$ for activity planning) and between $\mathrm{L}$ carriers and non-carriers $(\mathrm{F}=$ $0.90, \mathrm{p}=0.34$ for total CSM; $\mathrm{F}=0.25, \mathrm{p}=0.62$ for morningness; $\mathrm{F}=$ $2.42, \mathrm{p}=0.12$ for morning alertness; and $\mathrm{F}=0.64, \mathrm{p}=0.42$ for activity planning).

\section{DISCUSSION}

The aim of the present study was to investigate the association between the 5-HTTLPR polymorphism and diurnal preference; however, no statistically significant results were found.

To the best of our knowledge, this is the first study to investigate the association between 5-HTTLPR and diurnal preference in an Asian population. Previous studies on the relationship between 5-HTTLPR and diurnal preference have reported inconsistent findings. Ojeda et al. [32] found a significant association in a sample of 191 young South American adults, while Barclay et al. [33] found no such association in 947 young British adults. Both studies used linear regression analysis corrected for sex and age. In Barclay's study, the interaction of negative life events was additionally considered, but it did not change the result. Such inconsistencies in previous findings could be explained by two reasons. First, as Barclay claimed, the sample sizes of the previous 
studies may have been limited, and a larger sample might be needed to confirm a solid conclusion [33]. Second, it may be due to differences in ethnicity, culture, and social environment of the sample population, which may influence the 5-HTTLPR effect. For instance, ethnicity was found to moderate the association between 5-HTTLPR and national suicide rates; the $\mathrm{S}$ allele was a protective factor in Caucasians and a risk factor in non-Caucasian populations [34]. Further studies with a large number of subjects from multiple ethnicities and cultural factors are necessary to fully evaluate the association between 5-HTTLPR and diurnal preference.

The current study has several limitations. First, population stratification bias cannot be excluded. However, since the Korean population shows a relatively high degree of genetic homogeneity and the enrolled subjects consisted of healthy young Korean adults, the possibility of population stratification bias in this study seems unlikely [35]. Second, although our sample size was sufficient for statistical significance, it may not be sufficient to test a single-nucleotide polymorphism effect underlying the complexity of diurnal preference. Third, our study evaluated the two variants of the 5-HTTLPR polymorphism, $\mathrm{S}$ allele and $\mathrm{L}$ allele, which may obscure the more intrinsic interaction and effect of other 5-HTTL$P R$ polymorphisms. The assumed functionally bi-allelic 5-HTTL$P R$ polymorphism may not accurately represent the true association between 5-HTTLPR and diurnal preference [36]. Fourth, environmental effects or stress events that might influence the subject's diurnal preference or effect of 5-HTTLPR were not considered in this study. Although diurnal preference is largely genetic, socialenvironmental factors also affect diurnal preference [37]. And though controversial, several meta-analyses found a significant gene-environment interaction between stress and 5-HTTLPR polymorphism [38,39]. Although most of our participants were college students, no information about involving shift-working jobs or assessment of life stress events was not included.

In conclusion, this study did not find a statistically significant association between the 5-HTTLPR polymorphism and diurnal preference in the Korean population. Due to limited research, our understanding of the genetic effects associated with diurnal preference is inadequate. Future studies may find additional genes associated with diurnal preference and improve our understanding of the genetic effects on the phenotypic expression of circadian rhythmicity. As many psychiatric disorders are associated with circadian rhythms, further research may lead to valuable treatment strategies.

\section{Acknowledgments}

This study was supported by the Korea Health 21 R\&D Project funded by the National Research Foundation of Korea (2017M3 A9F1031220 and 2019R1A2C2084158).

\section{Conflicts of Interest}

The authors have no potential conflicts of interest to disclose.

\section{Author Contributions}

Conceptualization: Heon-Jeong Lee. Data curation: Ju Yeon Seo, Ji Won Yeom, Sehyun Jeon. Formal analysis: Sae Han Kim, HeonJeong Lee. Funding acquisition: Heon-Jeong Lee. Investigation: Sae Han Kim, Seunghwa Jeong. Methodology: Sae Han Kim, Seunghwa Jeong, Ji Won Yeom, Sehyun Jeon. Project administration: Ju Yeon Seo, Heon-Jeong Lee. Resources: Heon-Jeong Lee. Software: Sae Han Kim, Seunghwa Jeong, Ji Won Yeom, Sehyun Jeon. Supervision: Heon-Jeong Lee. Validation: Heon-Jeong Lee. Visualization: Sae Han Kim. Writing_original draft: Sae Han Kim, Writing_-review \& editing: Heon-Jeong Lee.

\section{ORCID iDs}

Sae Han Kim (1)

https://orcid.org/0000-0002-8969-5296

Ji Won Yeom (1)

https://orcid.org/0000-0003-0038-2101

Seunghwa Jeong

https://orcid.org/0000-0003-3850-9243

Ju Yeon Seo (1)

https://orcid.org/0000-0003-1312-761X

Sehyun Jeon (1)

https://orcid.org/0000-0002-6594-6556

Heon-Jeong Lee (1)

https://orcid.org/0000-0002-9560-2383

\section{REFERENCES}

1. Adan A, Archer SN, Hidalgo MP, Di Milia L, Natale V, Randler C. Circadian typology: a comprehensive review. Chronobiol Int 2012;29:1153-1175.

2. Partonen T. Chronotype and health outcomes. Curr Sleep Med Rep 2015; 1:205-211.

3. Fischer D, Lombardi DA, Marucci-Wellman H, Roenneberg T. Chronotypes in the US - influence of age and sex. PLoS One 2017;12:e178782.

4. Barclay NL, Rowe R, O'Leary R, Bream D, Gregory AM. Longitudinal stability of genetic and environmental influences on the association between diurnal preference and sleep quality in young adult twins and siblings. J Biol Rhythms 2016;31:375-386.

5. Liu AC, Welsh DK, Ko CH, Tran HG, Zhang EE, Priest AA, et al. Intercellular coupling confers robustness against mutations in the SCN circadian clock network. Cell 2007;129:605-616.

6. Takahashi JS, Hong HK, Ko CH, McDearmon EL. The genetics of mammalian circadian order and disorder: implications for physiology and disease. Nat Rev Genet 2008;9:764-775.

7. Ciarleglio CM, Resuehr HE, McMahon DG. Interactions of the serotonin and circadian systems: nature and nurture in rhythms and blues. Neuroscience $2011 ; 197: 8-16$.

8. Deurveilher S, Semba K. Indirect projections from the suprachiasmatic nucleus to major arousal-promoting cell groups in rat: implications for the circadian control of behavioural state. Neuroscience 2005;130:165-183.

9. Mistlberger RE, Bossert JM, Holmes MM, Marchant EG. Serotonin and feedback effects of behavioral activity on circadian rhythms in mice. Behav Brain Res 1998;96:93-99.

10. Morin LP, Allen CN. The circadian visual system, 2005. Brain Res Rev 2006; 51:1-60.

11. Malek ZS, Sage D, Pévet P, Raison S. Daily rhythm of tryptophan hydroxylase- 2 messenger ribonucleic acid within raphe neurons is induced by corticoid daily surge and modulated by enhanced locomotor activity. Endocrinology 2007;148:5165-5172.

12. Song HM, Cho CH, Lee HJ, Moon JH, Kang SG, Yoon HK, et al. Association of CLOCK, ARNTL, PER2, and GNB3 polymorphisms with diurnal 
preference in a Korean population. Chronobiol Int 2016;33:1455-1463.

13. Parsons MJ, Lester KJ, Barclay NL, Archer SN, Nolan PM, Eley TC, et al. Polymorphisms in the circadian expressed genes PER3 and ARNTL2 are associated with diurnal preference and GN $\beta 3$ with sleep measures. J Sleep Res 2014;23:595-604.

14. Perea CS, Niño CL, López-León S, Gutiérrez R, Ojeda D, Arboleda H, et al. Study of a functional polymorphism in the PER3 gene and diurnal preference in a Colombian sample. Open Neurol J 2014;8:7-10.

15. Lee JH, Kim SJ, Lee SY, Hwang JW, Suh IB. Association of PER2 and CRY1 polymorphisms with the morningness-eveningness in Korean adults. Sleep Med Res 2015;6:60-65.

16. Ju H, Cho CH, Moon JH, Kim L, Lee HJ. Association of the RORA gene polymorphism and diurnal preference in a young Korean population. Sleep Med Psychophysiol 2016;23:25-28

17. Yeom JW, Jeong S, Seo JY, Jeon S, Lee HJ. Association of the serotonin $2 \mathrm{~A}$ receptor rs6311 polymorphism with diurnal preference in Koreans. Psychiatry Investig 2020;17:1137-1142.

18. Nakamura M, Ueno S, Sano A, Tanabe H. The human serotonin transporter gene linked polymorphism (5-HTTLPR) shows ten novel allelic variants. Mol Psychiatry 2000;5:32-38.

19. Karg K, Burmeister M, Shedden K, Sen S. The serotonin transporter promoter variant (5-HTTLPR), stress, and depression meta-analysis revisited: evidence of genetic moderation. Arch Gen Psychiatry 2011;68:444-454.

20. Rosenthal NE, Mazzanti CM, Barnett RL, Hardin TA, Turner EH, Lam GK, et al. Role of serotonin transporter promoter repeat length polymorphism (5-HTTLPR) in seasonality and seasonal affective disorder. Mol Psychiatry 1998;3:175-177.

21. Murakami F, Shimomura T, Kotani K, Ikawa S, Nanba E, Adachi K. Anxiety traits associated with a polymorphism in the serotonin transporter gene regulatory region in the Japanese. J Hum Genet 1999;44:15-17.

22. Nellissery M, Feinn RS, Covault J, Gelernter J, Anton RF, Pettinati H, et al. Alleles of a functional serotonin transporter promoter polymorphism are associated with major depression in alcoholics. Alcohol Clin Exp Res 2003; 27:1402-1408.

23. van der Meer D, Hartman CA, Richards J, Bralten JB, Franke B, Oosterlaan J, et al. The serotonin transporter gene polymorphism 5-HTTLPR moderates the effects of stress on attention-deficit/hyperactivity disorder. J Child Psychol Psychiatry 2014;55:1363-1371.

24. Devlin B, Cook EH Jr, Coon H, Dawson G, Grigorenko EL, McMahon W, et al. Autism and the serotonin transporter: the long and short of it. Mol Psychiatry 2005;10:1110-1116.

25. Nam YJ, Cho CH, Kim L, Lee HJ. Association of G-protein $\beta 3$ subunit C825T polymorphism with seasonal variations in mood and behavior. Psychiatry Investig 2018;15:200-204.
26. Kim HI, So SJ, Yang HJ, Song HM, Moon JH, Yoon HK, et al. Association of the RORA gene polymorphism and seasonal variations in mood and behavior. Sleep Med Psychophysiol 2013;20:63-68.

27. Kim HI, Lee HJ, Cho CH, Kang SG, Yoon HK, Park YM, et al. Association of CLOCK, ARNTL, and NPAS2 gene polymorphisms and seasonal variations in mood and behavior. Chronobiol Int 2015;32:785-791.

28. Smith CS, Reilly C, Midkiff K. Evaluation of three circadian rhythm questionnaires with suggestions for an improved measure of morningness. J Appl Psychol 1989;74:728-738.

29. Greenwood KM. Long-term stability and psychometric properties of the composite scale of morningness. Ergonomics 1994;37:377-383.

30. Randler C, Díaz-Morales JF. Morningness in German and Spanish students: a comparative study. Eur J Pers 2007;21:419-427.

31. Yoon JS, Shin SM, Kook SH, Lee HY. A preliminary study on the Korean Translation of Composite Scale (KtCS) to measure morningness: eveningness. J Korean Neuropsychiatr Assoc 1997;36:122-134.

32. Ojeda DA, Perea CS, Suárez A, Niño CL, Gutiérrez RM, López-León S, et al. Common functional polymorphisms in SLC6A4 and COMT genes are associated with circadian phenotypes in a South American sample. Neurol Sci 2014;35:41-47.

33. Barclay NL, Eley TC, Mill J, Wong CC, Zavos HM, Archer SN, et al. Sleep quality and diurnal preference in a sample of young adults: associations with 5HTTLPR, PER3, and CLOCK 3111. Am J Med Genet B Neuropsychiatr Genet 2011;156B:681-690.

34. Schild AH, Nader IW, Pietschnig J, Voracek M. Ethnicity moderates the association between 5-HTTLPR and national suicide rates. Arch Suicide Res 2014;18:1-13.

35. Han GR, Lee YW, Lee HL, Kim SM, Ku TW, Kang IH, et al. A Korean population study of the nine STR loci FGA, VWA, D3S1358, D18S51, D21S11, D8S1179, D7S820, D13S317 and D5S818. Int J Legal Med 2000;114:41-44.

36. Goldman N, Glei DA, Lin YH, Weinstein M. The serotonin transporter polymorphism (5-HTTLPR): allelic variation and links with depressive symptoms. Depress Anxiety 2010;27:260-269.

37. Barclay NL, Watson NF, Buchwald D, Goldberg J. Moderation of genetic and environmental influences on diurnal preference by age in adult twins. Chronobiol Int 2014;31:222-231.

38. Sharpley CF, Palanisamy SK, Glyde NS, Dillingham PW, Agnew LL. An update on the interaction between the serotonin transporter promoter variant (5-HTTLPR), stress and depression, plus an exploration of non-confirming findings. Behav Brain Res 2014;273:89-105.

39. Bleys D, Luyten P, Soenens B, Claes S. Gene-environment interactions between stress and 5-HTTLPR in depression: a meta-analytic update. J Affect Disord 2018;226:339-345. 